\title{
Effect of Dietary Sorbitol on Growth Performance and Plasma Acute Phase Protein Concentration in Male Broiler Chickens during Immunological Stimulation
}

\author{
Kazuaki Takahashi" ${ }^{1)}$, Kenji Kawamata"), Yukio Akiba ${ }^{1)}$ \\ and Toru Okada ${ }^{2)}$ \\ ${ }^{2)}$ Kyowa Hakko Kogyo Co., Ltd. Tokyo, 100-8185.
}

\begin{abstract}
Two experiments were conducted to determine effect of dietary sorbitol on growth performance, plasma $\alpha 1$ acid glycoprotein (AGP) and ceruloplasmin concentrations in male broiler chicks during immunological stimulation due to injections with Escherichia coli lipopolysaccharide (LPS) and Sephadex-G50 superfine. In experiment 1, 10 days old chicks were fed a $6 \%$ glucose, xylitol, sorbitol or fructose for 8 days. In experiment 2, 7 days old chicks were fed either diet containing $10 \%$ glucose or sorbitol supplemented diet for 12 days. During final 6 days of the experimental periods, all chicks in experiment 1 and a half of birds fed each diet in experiment 2 were injected intraperitoneally with Escherichia coli LPS $(0.5 \mathrm{mg} / \mathrm{kg} \mathrm{BW})$ on days 1,3 and 5 and Sephadex $(250 \mathrm{mg} / \mathrm{kg} \mathrm{BW})$ on days 2 and 4 . Chicks fed the sorbitol diets tended to be better in growth performance than birds fed the glucose or fructose diet in experiment 1 . In experiment 2, feeding the sorbitol diet prevented the reductions in body weight gain due to LPS and Sephadex injections. Plasma AGP concentration on day 2 after the immune stimulation in chicks fed the sorbitol diet was lower than that in chicks fed the glucose diet, but that on day 6 did not differ. Plasma ceruloplasmin concentration on days 2 and 6 after the immune stimulation in chicks fed the sorbitol diet was significantly lower than that in chicks fed the glucose diet. These results indicate that dietary sorbitol reduces early inflammatory responses and tended to prevent the reduction of growth due to repeated injections of LPS and Sephadex. In addition, mode of action of sorbitol in preventing growth retardation during immunological stimulation appeared to be different from that of xylitol, which was previously reported in chicks.
\end{abstract}

Key word : Dietary sorbitol, Immunological stimulation, Inflammatory responses, Performance, Chicks

\section{Introduction}

Nutritional regulation of immune-induced decreases in performance would be of great value to the poultry industry. One of the goals for controlling immune system by nutrition is to alleviate decreased performances following immune stimulation without

Received: October 24, 2001 Accepted : December 14, 2001

Correspondence to : K Takahashi

Laboratory of Animal Nutrition, Graduate School of Agricultural Science, Tohoku University,

Akoba-ku, Sendai-shi 981-8555

Tel : 022-717-8690 Fax : 022-717-8691 E-mail : taka@bios.tohoku.ac.jp 
changes in the immune responses in domestic animals. Inflammatory responses following immune stimulation were often accompanied by a markedly stimulated tissue glucose use in hosts and this increased peripheral glucose use may support cellular functions responsible for the protection of hosts (Klasing, 1988; Klasing and Johnstone, 1991 ; Spolarics 1995). Benson et al. (1993) showed that increasing energy density by cornstarch, but not by oil (corn oil), eliminated the growth depressing effect of immunogen and prevented an increase in interleukin (IL)-1 production in chicks when dietary energy level was above $13.4 \mathrm{~kJ} / \mathrm{kg}$ diet. Takahashi et al. (1999; 2000) demonstrated that supplementation of xylitol (five-carbon sugar alcohol) had the similar effects on growth preferences as the cornstarch supplementation under condition of immunological stimulation by LPS and Sephadex injections. However, Takahashi et al. $(1999 ; 2000)$ suggested that the effect of xylitol was not due to increased energy content in diet as observed in the cornstarch, because xylitol supplementation did not affect production of pro-inflammatory cytokines such as IL-1, 6, and tumor necrosis factor.

Non-glucose monosaccharides, expecially sugar alcohols such as sorbitol and xylitol, and fructose have been advocated for use by parenteral infusion for nutritional support in patients suffered from the trauma and severe infections (Levine, 1985). Sorbitol and xylitol have been shown to elicit little or no increases in blood glucose and insulin in human (De Kalbermatten., 1980). Ellwood et al. (1999) also showed that sorbitol had similar effect on lipogenic and gluconeogenic enzymes, plasma hormones, lipids, catecholamines in rats as xylitol. Thus, sorbitol may have similar nature as xylitol in many metabolic aspects and serve as a nutrient for modulating metabolic processes during immune stimulation. However, there is little information on effect of sorbitol on growth performance and early inflammatory responses in immune stimulated chicks.

In the present study, we determined if dietary sorbitol have beneficial effects on performances during immune stimulation similarly to dietary xylitol in male broiler chickens.

\section{Materials and Methods}

In experiment 1 , male broiler chicks (Ross) were housed in battery brooder with electronic heater and fed a commercial broiler starter diet until 10 days of age. Forty chicks were selected from one and half larger population to obtain uniform body weight. They were randomly assigned to 4 groups of 10 chicks, with 5 replicates of 2 chicks in a cage, and were given the test diets supplemented with either $6 \%$ glucose, xylitol, sorbitol or fructose for 8 days ad libitum. A basal (glucose) diet consisted of $47.87 \%$ corn, $30.00 \%$ soybean meal, $3.99 \%$ isolated soybean protein, $3.64 \%$ soybean oil, $10.00 \%$ glucose, $1.21 \%$ calcium carbonate, $1.78 \%$ calcium phosphate, $0.42 \%$ sodium chloride, $0.29 \%$ DL-methionine, $0.40 \%$ vitamin mixture and $0.40 \%$ mineral mixture $(22 \%$ crude protein and $3100 \mathrm{kcal} / \mathrm{kg}$ metabolizable energy). Xylitol, fructose and sorbitol in the test diets were replaced by $6 \%$ of glucose in the basal diet. During final 6 days of the test diets feeding, chicks were intraperitoneally injected with 
Escherichia coli lipopolysaccharide (LPS, 0127B : B8, Difco Laboratories, Detroit, USA) at $0.5 \mathrm{mg} / \mathrm{kg} \mathrm{BW}$ on days 1, 3 and 5 and with Sephadex-G50 (Pharmacia Biotech AB, Uppsala, Sweden) at $250 \mathrm{mg} / \mathrm{kg} \mathrm{BW}$ on days 2 and 4 . LPS was dissolved in sterilized saline at a concentration of $0.5 \mathrm{mg} / \mathrm{ml}$. Sephadex G-50 superfine was dissolved at $5 \mathrm{~g}$ in $100 \mathrm{ml}$ in a sterilized saline $(0.9 \% \mathrm{NaCl})$.

In experiment 2 , forty male broiler chicks ( 7 days of age) were used. They were randomly assigned to 2 groups of 20 chicks, with 10 replicates of 2 chicks in a cage, and were given the test diets containing either $10 \%$ glucose or sorbitol supplemented diet for 12 days ad libitum. Composition in the glucose and sorbitol diet was the same as in experiment 1 except for amount of glucose and sorbitol. At 14 days of age immune stimulation by LPS and Sephadex was started. Half of chicks fed the each diet were intraperitoneally injected with Escherichia coli lipopolysaccharide (LPS) at $0.5 \mathrm{mg} / \mathrm{kg}$ BW on days 1, 3 and 5 and with Sephadex-G50 at $250 \mathrm{mg} / \mathrm{kg}$ BW on days 2 and 4 . The other half of birds in the each dietary group was served as the control chicks. They were injected with sterilized saline alone in the same manner as in the LPS and Sephadex injected groups. A blood was taken on days 2 and 6 following the immune simulation.

The method of determination of $\alpha-1$ acid glycoprotein (AGP) concentrations in plasma were reported previously (Takahashi et al., 1994). Plasma ceruloplasmin was determined by the procedure of Sunderman and Nomoto (1970). The analyses for feed intake, and weight gain to feed intake ratio were based on cage replication. For analyses of the other measurements, individual chicks were considered as experimental unit. A 2 (dietary groups) by 2 (immune stimulation) factorial statistical test was applied to analyze the data using of SAS (SAS Institute, Cary, NC, USA) with mean separation by Duncan's multiple range test in experiment 2. The data of experiment 1 were analyzed using one way ANOVA (SAS Institute, Cary, NC, USA) with mean separation by Duncan's multiple range test. For analyses of body weight, feed intake and body weight to feed intake ratio, the analyses were based on cage replication. For analysis of AGP and ceruloplasmin concentrations in plasma, individual chicks were considered as experimental unit.

\section{Results}

Table 1 shows the results of experiment 1 . Body weight gain and feed intake during immunological stimulation due to repeated injections of LPS and Sephadex in chicks fed the $6 \%$ xylitol diet were significantly greater than those in chicks fed the $10 \%$ glucose or fructose diet. Compared with the control chicks fed the glucose diet, feeding the $6 \%$ sorbitol diet also improved body weight gain during immunological stimulation. Body weight gain to feed intake ratio did not significantly differ among the dietary treatments, although that in chicks fed the glucose diet tended to be lower than that in chicks fed the other diets.

Table 2 shows growth performance in male broiler chicks fed the sorbitol diet for 7 days before immune stimulation in experiment 2. Growth performance before immune stimulation from 7 to 14 days of age did not significantly differ between chicks 
Takahashi et al. : Dietary Sorbitol and Inflammatory Response

Table 1. Effect of dietary glucose, xylitol, sorbitol and fructose on growth performance following repeated injections of LPS and Sephadex in male broiler chicks (Experiment 1$)^{\mathrm{l}}$

\begin{tabular}{llcc}
\hline \multicolumn{1}{c}{ Diet } & $\begin{array}{c}\text { Feed intake } \\
(\mathrm{g})\end{array}$ & $\begin{array}{c}\text { Body weight gain } \\
(\mathrm{g})\end{array}$ & $\begin{array}{c}\text { Body weight gain } \\
\text { Feed intake }\end{array}$ \\
\hline Glucose & $223 \pm 10 \mathrm{~b}$ & $127 \pm 6 \mathrm{~b}$ & $0.569 \pm 0.054$ \\
Xylitol & $250 \pm 7 \mathrm{a}$ & $150 \pm 6 \mathrm{a}$ & $0.601 \pm 0.037$ \\
Sorbitol & $237 \pm 8 \mathrm{ab}$ & $147 \pm 5 \mathrm{a}$ & $0.618 \pm 0.034$ \\
Fructose & $230 \pm 14 \mathrm{~b}$ & $140 \pm 6 \mathrm{ab}$ & $0.610 \pm 0.021$ \\
\hline
\end{tabular}

Mean $\pm \mathrm{SE}$ (observations $=5$ ). $\mathrm{a}, \mathrm{b}: \mathrm{P}<0.05$.

fed the glucose and sorbitol diet although chicks fed the $10 \%$ sorbitol diet tended to be lesser growth performance than chicks fed the $10 \%$ glucose diet.

Table 3 shows growth performance in male broiler chicks fed the sorbitol diet during immunological stimulation by repeated injection of LPS and Sephadex in experiment 2. Repeated injections of LPS and Sephadex significantly reduced feed intake, body weight gain and body weight to feed intake ratio. Body weight gain during immunological stimulation was improved by feeding the sorbitol diet compared with the feeding glucose diet. Feed intake and body weight gain to feed intake ratio during immune stimulation were not changed by the sorbitol diet.

Table 4 shows changes in plasma AGP and ceruloplasmin concentrations during immunological stimulation by repeated injection of LPS and Sephadex in experiment 2. Alternating injections of LPS and Sephadex increased plasma ceruloplasmin and AGP concentrations irrespective of days of the injection and dietary treatments. Dietary sorbitol partially prevented increasing plasma ceruloplasmin concentrations due to

Table 2. Effect of dietary sorbitol on growth performance before immunological stimulation

In male broiler chicks (Experiment 2, from 7 to 14 days of age)"

\begin{tabular}{rccc}
\hline \hline Diet & $\begin{array}{c}\text { Feed intake } \\
(\mathrm{g})\end{array}$ & $\begin{array}{c}\text { Body weight gain } \\
(\mathrm{g})\end{array}$ & $\begin{array}{c}\text { Body weight gain } \\
\text { Feed intake }\end{array}$ \\
\hline Glucose & $644 \pm 19$ & $477 \pm 9$ & $0.724 \pm 0.014$ \\
Sorbitol & $626 \pm 15$ & $458 \pm 9$ & $0.732 \pm 0.014$ \\
\hline
\end{tabular}

Mean $\pm \mathrm{SE}$ (observations $=10)$.

Table 3. Effect of dietary sorbitol on growth performance after repeated injections of LPS and Sephade for 6 days in male broiler chicks (Experiment 2)

\begin{tabular}{|c|c|c|c|c|c|c|c|}
\hline \multirow{2}{*}{$\begin{array}{l}\text { Diet } \\
\text { Treatment }\end{array}$} & \multicolumn{2}{|c|}{ Glucose } & \multicolumn{2}{|c|}{ Sorbitol } & \multicolumn{3}{|c|}{ ANOVA } \\
\hline & Saline & $\begin{array}{c}\text { LPS } \\
+ \text { Sepadex }\end{array}$ & Saline & $\begin{array}{c}\text { LPS } \\
+ \text { Sepadex }\end{array}$ & Diet & $\begin{array}{c}\text { LPS } \\
+ \text { Sepadex }\end{array}$ & $\begin{array}{l}\text { Diet } \mathrm{X} \\
\text { Treatment }\end{array}$ \\
\hline Feed intake $(\mathrm{g})$ & $459 \pm 14 a$ & $412 \pm 15 b$ & $459 \pm 20 \mathrm{a}$ & $397 \pm 13 b$ & NS & $<0.01$ & NS \\
\hline Body weight gain $(g)$ & $288 \pm 10 \mathrm{a}$ & $235 \pm 6 \mathrm{c}$ & $283 \pm 9 a$ & $258 \pm 5 b$ & NS & $<0.01$ & $<0.1$ \\
\hline $\begin{array}{l}\text { Body weight gain } \\
\text { /Feed intake }\end{array}$ & $0.62 \pm 0.03$ & $0.58 \pm 0.03$ & $0.63 \pm 0.01$ & $0.60 \pm 0.03$ & NS & $<0.01$ & NS \\
\hline
\end{tabular}

Mean $\pm \mathrm{SE}$ (observations $=5$ ). $\quad \mathrm{a}, \mathrm{b}: \mathrm{P}<0.05 . \quad \mathrm{NS}:>0.1$. 
Table 4. Effect of dietary sorbitol on plasma AGP and ceruloplasmin concentration following repeated injections of LPS and Sephade for 6 days in male broiler chicks (Experiment 2)

\begin{tabular}{|c|c|c|c|c|c|c|c|}
\hline \multirow{2}{*}{$\begin{array}{c}\text { Diet } \\
\text { Treatment }\end{array}$} & \multicolumn{2}{|c|}{ Glucose } & \multicolumn{2}{|c|}{ Sorbitol } & \multicolumn{3}{|c|}{ ANOVA } \\
\hline & Saline & $\begin{array}{c}\text { LPS } \\
+ \text { Sepadex }\end{array}$ & Saline & $\begin{array}{c}\text { LPS } \\
+ \text { Sepadex }\end{array}$ & Diet & $\begin{array}{c}\text { LPS } \\
+ \text { Sepadex }\end{array}$ & $\begin{array}{c}\text { Diet } X \\
\text { Treatment }\end{array}$ \\
\hline \multicolumn{8}{|c|}{ Ceruloplasmin $(\mathrm{mg} / \mathrm{l})$} \\
\hline Day 2 & $25 \pm 3 c$ & $88 \pm 7 a$ & $29 \pm 6 c$ & $69 \pm 7 b$ & NS & $<0.01$ & $<0.1$ \\
\hline Day 6 & $21+3 c$ & $61 \pm 8 \mathrm{a}$ & $23 \pm 3 c$ & $35 \pm 4 b$ & $<0.05$ & $<0.01$ & $<0.01$ \\
\hline \multicolumn{8}{|l|}{$\operatorname{AGP}(\mathrm{mg} / l)$} \\
\hline Day 2 & $213 \pm 17 c$ & $708 \pm 33 a$ & $253+43 \mathrm{c}$ & $599 \pm 40 \mathrm{~b}$ & NS & $<0.01$ & $<0.05$ \\
\hline Day 6 & $183 \pm 17 b$ & $674 \pm 51 \mathrm{a}$ & $217 \pm 25 b$ & $665 \pm 47 a$ & NS & $<0.01$ & NS \\
\hline
\end{tabular}

repeated injections of LPS and Sephadex on days 2 and 6. Plasma AGP concentration on day 2 after immune stimulation was lower in chicks fed the sorbitol diet than chicks fed the glucose diet, but that on day 6 did not differ.

\section{Discussion}

The present experiment showed that dietary sorbitol partly prevented a decrease in body weight gain caused by immunological stimulation due to alternating injections of LPS and Sephadex. This sorbitol effect was similar as effect of xylitol as previously reported (Takahashi et al., 1999 ; 2000). However, mode of action of dietary sorbitol on growth performance during immune stimulation may be different from that of xylitol. AGP and ceruloplasmin are known as positive acute phase proteins in response to immunological stress and would be produced following pro-inflammatory cytokines such as interleukin-1 6, and tumor necrosis factor (Takahashi et al., 1994 and 1998 ; Chamanza et al., 1999). Takahashi et al. (1999; 2000) observed that dietary xylitol did not affect production of interleukin-1 like activity and acute phase protein concentrations such as AGP and ceruloplasmin in plasma, suggesting that dietary xylitol did not affect production and/or release of pro-inflammatory cytokines. On the other hand, dietary sorbitol significantly prevented to increase in plasma AGP concentration on day 2 and ceruloplasmin concentrations on days 2 and 6 following immunological stimulation in the present study. Thus, effect of dietary sorbitol on growth performance may be associated with reduction of pro-inflammatory cytokines production during immunological stress.

Cook et al. (1993) and Miller et al. (1994) found that conjugated linoleic acid (CLA), a structural isomer of linoleic acid, was effective in preventing body weight loss following immune stimulation in chicks. Fish oil also improved performance and decreased the inflammatory responses in chicks (Korver and Klasing, 1997 ; Korver et al. 1998). Fish oil and CLA isomers are also effective in preventing immune-induced weight loss and anorexia, and may be effective in preventing excess production of pro-inflammatory cytokines and/or prostaglandin $\mathrm{E}_{2}$ ( $\mathrm{Li}$ and Watkins, 1998 ; Liu and Belury, Pariza et al., 2000 ; Turek et al., 1998). Takahashi et al., (2001) recently 
showed that CLA significantly prevented increasing plasma AGP and ceruloplasmin concentrations due to LPS injection. Thus, alleviating effect of dietary sorbitol on growth performance during immune stimulation appeared to be similar as CLA and fish oil.

In mammals, feeding diets containing sugar alcohols for long terms is often shown to decrease feed intake, which leads to decreased body weight gain (Hamalainen and Makinen, 1985 : Ellwood et al., 1999). In the present experiment, we observed that feed intake for 7 days before immune stimulation tended to be lower in chicks fed the sorbitol diet than that in chicks fed the glucose diet although the effect is not significant. Since reductions of feed intake and body weight gain are undesirable from the practical viewpoint, for use of sorbitol as a poultry diet we should give attention to its content in diet and periods of use. However, in the stressful conditions, such as vaccination or transportation, short terms supply of sorbitol may be useful.

In conclusions, dietary sorbitol reduced early inflammatory responses and tended to prevent the reduction of growth following immune stimulation due to repeated injections of LPS and Sephadex. However, the effect of sorbitol on growth and inflammatory responses appeared to be different from that of xylitol, which was previously reported in chicks (Takahashi et al., $1999 ; 2000$ ).

\section{Refefence}

Benson BN, Calvert CC, Roura E and Klasing KC. Dietary energy source and density modulate the expression of immunological stress in chicks. Journal of Nutrition, $123: 1714-1723$. 1993.

Chamanza R, Veen LV, Tivapasi MT and Toussaint MJM. Acute phase proteins in the domestic fowl. World Poultry Science Journal, $55: 61-71.1999$.

Cook ME, Miller CC, Park Y and Pariza M. Immune modulation by altered nutrient metabolism : nutritional control of immune-induced growth depression. Poultry Science, $72: 1301-1305.1993$.

De Kalbermatten N, Ravussin E, Maeder E, Geser C, Jequier E and Felber JP, Comparsion of glucose, fructose, sorbitol and xylitol utilization in humans during insulin suppression. Metabolism, $29: 62-67.1980$.

Ellwood KC, Bhathena SJ, Johannessen JN, Bryant MA and O'Donnell NW. Biomarkers used to assess the effect of dietary xylitol or sorbitol in the rats. Nutrition Research, $19: 16326^{-}$ 1648. 1999.

Hamalainen MH. and Makinen KK. Metabolic effects in rat of high oral doses of galactitol, mannitol and xylitol. Journal of Nutrition, $115: 890-899.1985$.

Klasing KC. Nutritional aspects of leukocytic cytokines. Journal of Nutrition, 118:1436-1446. 1988.

Klasing KC and Johnstone BJ. Monokines in growth and development. Poultry Science, 70 : 1176-1186. 1991.

Korver DR. and Klasing KC. Dietary fish oil alters specific and inflammatory immune responses in chicks. Journal of Nutrition, $127:$ 2039-2046. 1997.

Korver DR, Roura E and Klasing KC. Effect of dietary energy level and oil source on broiler performance and response to an inflammatory challenge. Poultry Science, $77: 1217-1227$. 1998.

Levine R. Monosaccharides in health and disease. Annual Reviews of Nutrition, 6:211-224. 1986.

Li Y and Watkins BA. Conjugated linoleic acids alters bone fatty acid composition and reduce ex vivo prostaglandin E2 biosynthesis in rats fed $\mathrm{n}-6$ or $\mathrm{n}-3$ fatty acids. Lipids, $33: 417-425$. 
1998.

Liu KL and Belury MA. Conjugated linoleic acid reduces arachidonic acid content and PGE2 synthesis in murine keratinocytes. Cancer Letters, 127 : 15-22. 1998.

Miller CC, Park Y, Pariza MW and Cook ME. Feeding conjugated linoleic acid to animals partially overcomes catabolic responses due to endotoxin injection. Biochemical and Biophysics Research Communication, 198 : 1107-1112. 1994.

Pariza MW, Park Y and Cook ME. Mechanisms of action of conjugated linoleic acid : evidence and speculation. Proceedings of Society Experimental Biology and Medcine, 223 : 8-13. 2000.

Pellaton M, Acheson K, Maeder E, Jequier E and Felber JP. The comparative oxidation of glucose, fructose, sorbitol and xylitol in normal man. Journal Parenteral and Enteral Nutrition, 2 : 627-633. 1978.

SAS Institute Inc. 1982. SAS/STAT User's Guide : 1982 Edn. SAS Institiute Inc., Cary, North Carolina.

Spolarics Z and Spittzer JJ. Acute endtoxin tolerance is accompanied by stimulated glucose use in macrophage rich tissues. Biochemical and Biophysical Research Communication, 211 : 340-346. 1995.

Sunderman FW Jr. and Nomoto S. Measurement of human serum ceruloplasmin by its pphenylenediamine oxidase activity. Clinical Chemistry, $16: 903-910.1970$.

Takahashi K, Akiba Y, Iwata T and Kasai M. Dietary conjugated linoleic acids alleviates early inflammatory response caused by lipopolysaccharide injection in male broiler chicks. Animal Science Journal, 2002, in press.

Takahashi K, Kaji N, Akiba Y and Tamura K. Plasma alpha 1 acid glycoprotein concentration in broilers. Influence of age, sex and Escherichia coli lipopolysaccharide. British Poultry Science, $35: 427-432,1994$.

Takahashi K., Mashiko T, and Akiba Y. Effect of dietary concentration of xylitol on growth in male broiler chicks during immunological stress. Poultry Science, 79 : 743-747, 2000.

Takahashi K, Miyake N, Ohta T, Akiba Y and Tamura K. Changes in plasma $\alpha 1$-acid glycoprotein concentration and selected immune response in broiler chickens injected with Escherichia coli lipopolysaccharide. British Poultry Science, 39 : 152-155. 1998.

Takahashi K, Onodera K and Akiba Y. Effect of dietary xylitol on growth and inflammatory responses in immune stimulated chickens. British Poultry Science, 40 : 552-554. 1999.

Turek JJ, Li Y, Schoenlein I.A, Allen KGD and Watkins BA. Modulation of macrophage cytokine production by conjugated linoleic acids is influenced by the dietary n- $6: n-3$ fatty acid ratio. Journal of Nutritional Biochemistry, 9 : 258-266. 1998. 